\title{
Poly(ethylene-co-vinyl acetate)/clay nanocomposites: Effect of clay nature and organic modifiers on morphology, mechanical and thermal properties
}

\author{
S. Peeterbroeck ${ }^{\text {a }}$, M. Alexandre ${ }^{\text {a,b }}$, R. Jérôme ${ }^{\mathrm{c}}, \mathrm{Ph}$. Dubois ${ }^{\mathrm{a}}$ \\ ${ }^{a}$ Laboratory of Polymeric and Composite Materials, University of Mons-Hainaut, Place du Parc 20, 7000 Mons, \\ Belgium \\ ${ }^{\mathrm{b}}$ Materia Nova ASBL, Avenue N.Copernic 1, 7000 Mons, Belgium \\ ${ }^{\mathrm{c}}$ Centre for Education and Research on Macromolecules, University of Liège, Building B6, 4000 Liège, \\ Belgium
}

\begin{abstract}
Nanocomposites based on an ethylene vinyl acetate copolymer (27 wt \% vinyl acetate) and various (organomodified) clays have been prepared by melt blending and their morphology, tensile and thermal degradation properties have been evaluated. Special attention has been paid to the influence of the clay nature and origin (montmorillonite or fluoromica) as well as on the nature of the ammonium cation organic modifier. It has been shown that nanostructure and tensile properties mainly depend on the nature of the organic modifier while the delay in thermal volatilisation of EVA during thermo-oxidation is mainly driven by the nature of the clay (mainly its aspect ratio), with no significant influence of the nanostructure of the nature of the organic modifier.
\end{abstract}

Keywords: Ethylene vinyl acetate copolymer; Layered silicate; Tensile properties; Thermal degradation; Nanocomposite

\section{Introduction}

For more than 15 years, polymer/layered silicate nanocomposites have attracted the interest of polymer and materials scientists in filled polymers. Indeed, with tiny amounts (usually less then $5 \mathrm{wt} \%$ ), the addition of clay and its ultimate dispersion as $1 \mathrm{~nm}$-thick nanolayers in a polymer matrix allow many properties, such as stiffness, fire resistance, fluid and gas barrier properties,... to be increased [1-3]. Amongst various polymer matrices, the family of ethylene vinyl acetate copolymers (EVA) have been widely studied. Several studies have focussed on the effect of the vinyl acetate content on the dispersion of clay nanoplatelets, varying processing [4], addition of external compatibilisers [5,6] or the nature of the clay organo-modifier [6,7], for a given natural clay. In general, it has been observed that the higher the vinyl acetate content, the larger was the basal spacing increase of the clay, inducing the formation of intercalated to exfoliated nanostructures. An increase in the shear during the processing or the addition of compatibilisers, such as polyethylene grafted with maleic anhydride [6] or maleic anhydride directly [8] have been shown to improve greatly the final dispersion and distribution of the nanolayers as well as the tensile properties (stiffness) of EVA. Following an analogous idea, for a given EVA matrix, clay organo-modifiers (mostly ammonium cations) bearing polar groups such as hydroxyl groups have been shown to improve the nanolayer dispersion [9]. Various studies have also focussed on the effect of clay nanodispersion on properties such as rheology [9], fire and thermal resistance [10-14], tensile testing [10,11,15] or UV-visible transparency [15] for defined organo-modified clays and EVA matrices. Large improvements of these properties were observed only if a good dispersion of the nanolayers was achieved.

This study aims at determining the effect of clay nature (montmorillonite, fluoromica) and clay organo-modifier on the morphology, thermal and tensile properties of nanocomposites based on a defined grade of EVA $(27 \mathrm{wt} \%$ vinyl acetate). 


\section{Experimental part}

\subsection{Materials}

A commercial ethylene vinyl acetate copolymer (EVA), Escorene UL00328 (Exxon), containing $27 \mathrm{wt} \%$ of vinyl acetate (VA) and with a melt flow index $\left(190^{\circ} \mathrm{C} / 2.16 \mathrm{~kg}\right)$ of $3 \mathrm{~g} / 10 \mathrm{~min}$, was chosen as the matrix.

Commercial organoclays used were:

- from SouthernClay Products (USA): Cloisite ${ }^{\circledR} \mathrm{Na}$, a natural $\mathrm{Na}^{+}$montmorillonite; Cloisite ${ }^{\circledR}$ 20A, a montmorillonite modified by dimethyl bis(hydro-genated tallowalkyl)ammonium cations; Cloisite ${ }^{\circ} 25 \mathrm{~A}$ a montmorillonite modified by (2-ethylhexyl)-methyl (hydrogenated tallowalkyl)ammonium cations; Cloisite ${ }^{\circledR}$ 30B, a montmorillonite modified by bis(2-hydroxylethyl)methyl tallowalkyl ammonium cations;

- from Süd Chemie (Germany): Nanofil® 757, a natural $\mathrm{Na}^{\mathrm{C}}$ montmorillonite; Nanofil® 15, a montmorillonite modified by dimethyl bis(hydrogenated tallowalkyl)ammonium cations;

- from CO-OP Japan (Japan): Somasif ${ }^{\circledR}$ ME100, a non-modified $\mathrm{Na}^{\mathrm{C}}$ fluoromica; Somasif® MAE, fluoromica modified by dimethyl bis(hydrogenated tallowalkyl)ammonium cations.

Characteristic information of the used clays is given in Table 1. Interlayer distances were measured on asreceived and as-used clays (at room temperature and under atmospheric air). These measures might differ slightly (ca. $1 \AA \AA$ ) from producer determinations carried out on clay dried under vacuum at sub-ambient temperature.

\subsection{Preparation}

EVA and clay ( $5 \mathrm{wt} \%$ of organo-modified clays for morphology and $3 \mathrm{wt} \%$ in inorganics for mechanical and thermal properties) were compounded on an AGILA two-roll mill for 12 min at $140^{\circ} \mathrm{C}$ with a friction coefficient equal to 1.35 and a rotation speed of $15 \mathrm{~m} / \mathrm{s}$ for the slowest roll. Samples were obtained by compression moulding into $80 \times 100 \times 3 \mathrm{~mm}$ plates at $140{ }^{\circ} \mathrm{C}$.

Table 1: Characteristics of the various studied clays

\begin{tabular}{|c|c|c|c|}
\hline Filler & Interlayer cations & $\begin{array}{l}\text { Ammonium } \\
\text { content }^{3}\left(w t^{\%} \%\right)\end{array}$ & Interlayer distance $^{13}(\AA)$ \\
\hline Cloisite $\AA \mathrm{Na}$ & $\mathrm{Na}^{+}$ & 0 & 12.1 \\
\hline Cloisite ${ }^{\circledR} 20 \mathrm{~A}$ & $\left(\mathrm{CH}_{3}\right)_{2} \mathrm{~N}^{+}$(hydrogenated tallow $)_{2}$ & 29.2 & 22.4 \\
\hline Cloisite ${ }^{\circledR} 25 \mathrm{~A}$ & $\begin{array}{l}\left.\left(\mathrm{CH}_{3}\right)_{2} \mathrm{~N}^{+} \text {(hydrogenated tallow }\right)(2- \\
\text { ethylhexyl) }\end{array}$ & 26.9 & 20.7 \\
\hline Cloisite $\AA 30 \mathrm{~B}$ & $\left(\mathrm{CH}_{3}\right) \mathrm{N}^{+}$(tallow) $\left(\mathrm{CH}_{2} \mathrm{CH}_{2} \mathrm{OH}\right)_{2}$ & 20.3 & 18.5 \\
\hline Nanofil@ 757 & $\mathrm{Na}^{+}$ & 0 & 12.2 \\
\hline Nanofil@ 15 & $\left(\mathrm{CH}_{3}\right)_{2} \mathrm{~N}^{+}$(hydrogenated tallow $)_{2}$ & 28.9 & -29 (broad) \\
\hline Somasif $\AA$ ME100 $\mathrm{Na}^{+}$ & & 0 & 12.2 \\
\hline Somasif $₫$ MAE & $\left(\mathrm{CH}_{3}\right)_{2} \mathrm{~N}^{+}$(hydrogenated tallow $)_{2}$ & 40.8 & 31.1 \\
\hline
\end{tabular}

Tallow: Linear alkyl chains (C18 (65\%), C16 (30\%), C14 (5\%)) with 40\% mono-unsaturated chains.

${ }^{a}$ Determined by thermogravimetric analysis under helium atmosphere.

${ }^{\mathrm{b}}$ Determined by X-ray diffraction on as-received clays. 


\subsection{Characterization}

XRD was measured using a Siemens D5000 diffrac-tometer with the $\mathrm{Cu}$ Ka radiation (1 Z $0.15406 \mathrm{~nm})$ from 1.5 to $30^{\circ}$ by step of $0.04^{\circ}$. Transmission electron micrographs were obtained with a Philips CM100 apparatus using an accelerator voltage of $100 \mathrm{kV}$. The samples were 70-80 nm-thick and prepared with a Reichert Jung Ultracut $3 \mathrm{E}, \mathrm{FC} 4 \mathrm{E}$ ultracryomicrotome cutting at $-130^{\circ} \mathrm{C}$. Tensile properties were measured at $20^{\circ} \mathrm{C}$ on a Lloyd LR $10 \mathrm{~K}$ tensile tester with dumbell-shaped specimens obtained from compression moulded samples following ASTM D638 type V method. All tensile data were the average of five independent measurements; the relative errors are reported as well. Thermogravimetric analyses were performed on a TA instrument HiRes TGA 2950 thermogravimetric analyser with a heating ramp of $20 \mathrm{~K} / \mathrm{min}$ from room temperature to $625^{\circ} \mathrm{C}$ under air atmosphere.

\section{Results and discussion}

In this study we propose to compare various clays, differing by their origin (Nanofil $\AA$ from Europe or Cloisite $\AA$ from USA), their nature (montmorillonite or fluoromica) and the nature of the ammonium cations used as organo-modifiers. These clays have been dispersed in an EVA matrix ( $27 \mathrm{wt} \%$ vinyl acetate) by melt blending on a two-two roll mill at $140{ }^{\circ} \mathrm{C}$.

Two complementary techniques, i.e., X-ray diffraction (XRD) and transmission electron microscopy (TEM), were used to characterize the morphology of the prepared composites. For these analyses, the amount of organomodified clays was kept constant at $5 \mathrm{wt} \%$.

\subsubsection{X-ray diffraction}

Each prepared composite was analysed by XRD in order to evaluate whether intercalation occurs. The basal spacings of the clays and of the composites were calculated from the $\mathrm{d}_{001}$ peak in the X-ray diffracto-gram using the Bragg's equation and are given in Table 2.

Whatever the clay nature, dispersion of non-modified clays (Cloisite ${ }^{\circledR}$ Na, Nanofil ${ }^{\circledR} 757$ or Somasif $($ ME100) in EVA is characterized by the formation of micro-composites since no significant increase in the basal spacings recorded for these materials can be observed. In contrast, a mainly intercalated morphology, characterized by a well defined peak in XRD is obtained for the organoclays based on alkyl groups (Nanofil® 15, Cloisite 20 and 25A, Somasif® MAE). The largest basal spacings are observed for Nanofil@ 15 and Somasif® MAE but the bigger increase in interlayer distance is recorded for Cloisite ${ }^{\circledR} 25 \mathrm{~A}$ and Cloisite 20A. Such a high increase in interlayer spacings indicates a good affinity of EVA with the clay galleries organo-modified by alkyl-based organoclays. When comparing Cloisite ${ }^{\circledR} 20$ A, Nanofil ${ }^{\circledR} 15$ and Somasif ${ }^{\circledR}$ MAE, characterized by clays of various origins but organo-modified by the same ammonium cation (dimethyl bis(hydrogenated tallowalkyl)ammonium), one can remark that the final interlayer spacings are very close (between 38.7 and 40.4 Á) independent of the interlayer spacing of the used clays (29 A for Cloisite 20A or 22 A for Nanofil 15) or the amount of organo-modifier (ca. $29 \mathrm{wt} \%$ for Cloisite 20A or Nanofil 15 and $40.8 \mathrm{wt} \%$ for Somasif MAE).

Interestingly enough, upon melt blending with EVA, the organoclay bearing hydroxyl functions (Cloisite ${ }^{\circledR} 30 \mathrm{~B}$ ) gives a material characterized by the absence of any diffraction peak in the XRD pattern. The disappearance of the layer spacing of Cloisite ${ }^{\circledR}$ 30B after compounding with EVA implies either the formation of an intercalated nanocomposite with a basal spacing larger than $58 \AA$, the formation of an exfoliated structure or a very disorganized structure of the clay platelets. Further characterizations by TEM are necessary to determine exactly the structure of the Cloisite ${ }^{\circledR}$ 30B-based material.

It should be stressed out that, as far as interlayer distances are concerned, no variation of this value has been observed for composites based on the studied clays but with lower amount of fillers. 
Table 2: Interlayer spacing variation as obtained from diffraction peaks measured by DRX on clays and the resulting melt-blended EVA composites

\begin{tabular}{|c|c|c|c|}
\hline Filler & $\begin{array}{l}\text { Filler interlayer } \\
\text { distance }(\AA)\end{array}$ & $\begin{array}{l}\text { Composite interlayer } \\
\text { distance }(\AA)\end{array}$ & $\begin{array}{l}\text { Interlayer distance } \\
\text { variation }(\AA)\end{array}$ \\
\hline Cloisite $\AA \mathrm{Na}$ & 12.1 & 12.2 & 0.1 \\
\hline Cloisite ${ }^{\circledR} 20 \mathrm{~A}$ & 22.4 & 38.7 & 16.3 \\
\hline Cloisite ${ }^{\circledR} 25 \mathrm{~A}$ & 20.7 & 36.8 & 16.1 \\
\hline Cloisite ${ }^{\circledR} 30 \mathrm{~B}$ & 18.5 & - & - \\
\hline Nanofil@ 757 & 12.2 & 12.2 & 0 \\
\hline Nanofil@ 15 & ca. 29 (broad) & 40.2 & ca. 11 \\
\hline Somasif $₫$ ME100 & 12.2 & 12.3 & 0.1 \\
\hline Somasif® MAE & 31.1 & 40.4 & 9.3 \\
\hline
\end{tabular}

\subsubsection{Transmission electron microscopy}

More information on the nanocomposite morphology was obtained by TEM observation. Fig. 1 shows the microphotograph recorded for EVA filled with Nanofil ${ }^{\circledR} 15$. Stacks of silicate layers (2-10 sheets) can be observed, together with exfoliated nanoplatelets. The well-defined small and highly oriented stacks are responsible for the presence of a diffraction peak in DRX. These stacks however lack a very good distribution within the polymer matrix, where domains rich in stacks are located besides domains free of stacks (see Fig. 1a).

For the nanocomposite based on Cloisite ${ }^{\circledR} 25 \mathrm{~A}$ (Fig. 2), stacks of intercalated clay are also observed. However, these stacks are not well distributed in the EVA matrix and less isolated nanoplatelets are observed. TEM observation of this particular sample was furthermore difficult, due to the tendency of the sample to react towards the electron beam, more especially at the interface between the clay stacks and the polymer.

For the nanocomposite based on Cloisite ${ }^{\circledR}$ 30B (Fig. 3), a large extent of exfoliation is obtained, together with very small stacks (2-4 nanoplatelets). The relatively low amount of highly disordered stacks could explain the absence of diffraction peaks related to interlayer distances in this sample. Moreover, this sample is also characterized by a very homogeneous distribution of the clay nanoplatelets and stacks within the polymer matrix.

The exfoliation and distribution of the clay nano-platelets in the EVA matrix appear to depend on the nature of the clay organo-modifier. Indeed, the best results are obtained for Cloisite 30B, a clay organo-modified by ammonium cations bearing hydroxyl groups. This might result from interactions such as H-bonding between the hydroxyl groups of Cloisite 30B and the acetate functions of the EVA matrix. 

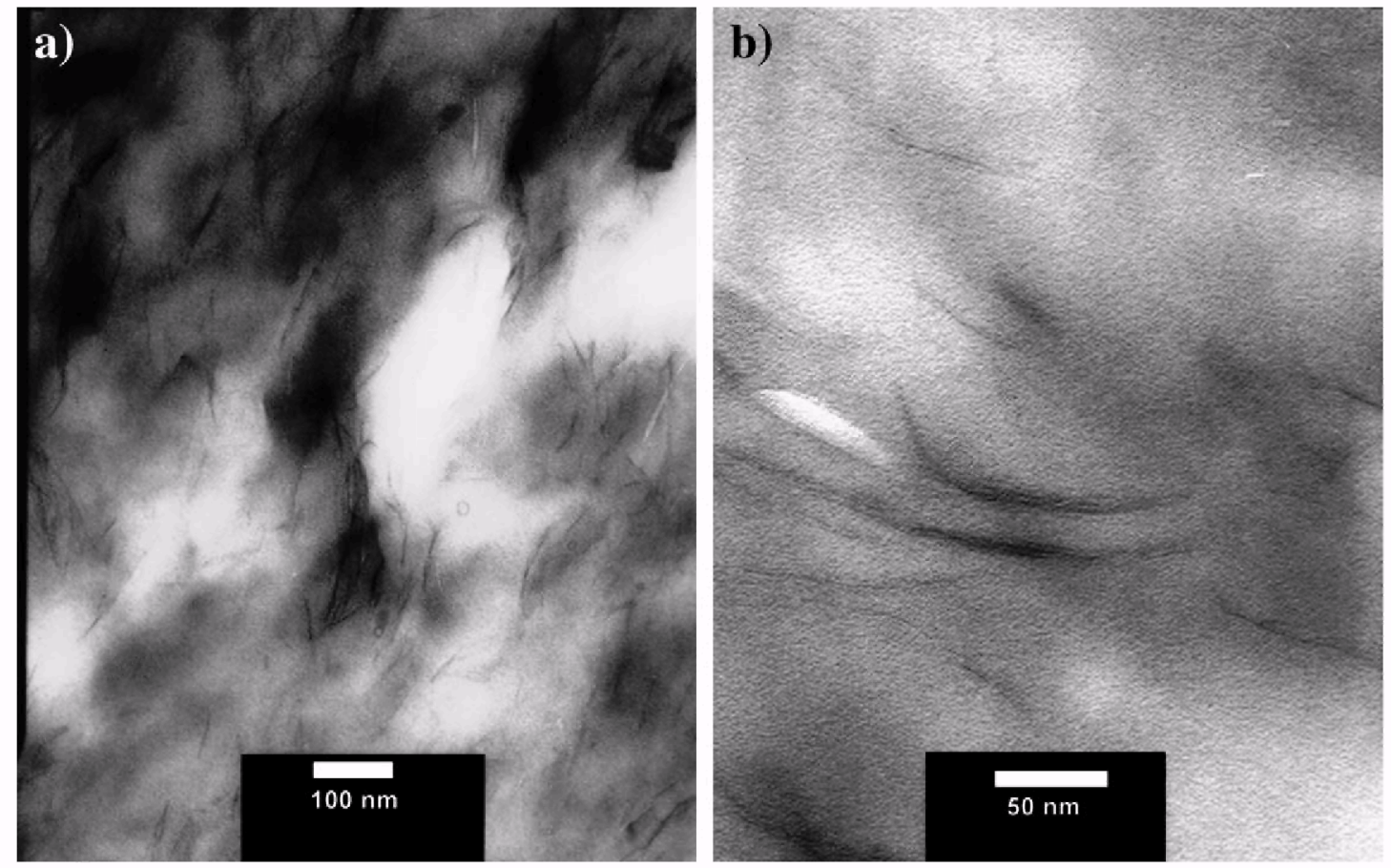

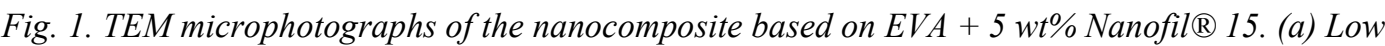
magnification, (b) high magnification.

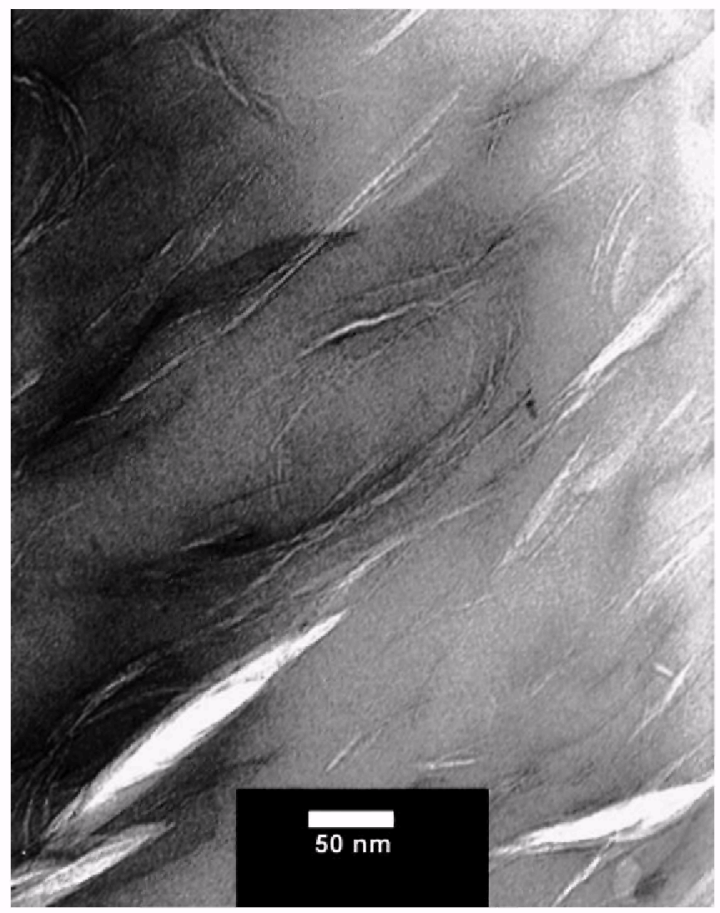

Fig. 2. TEM microphotograph of the nanocomposite based on EVA $+5 w t \%$ Cloisite ${ }^{\circledR} 25 A$. 


\subsection{Tensile properties}

In order to compare the effect of nanoclay dispersion and distribution on the mechanical (tensile) properties of the prepared nanocomposites, the same amount of clay (3 wt $\%$ in term of inorganic content) was used. Results of tensile testing in terms of stress and strain at break and Young's modulus are given in Table 3.

When comparing to the EVA matrix alone, the addition of non-organomodified clays (Cloisite ${ }^{\circledR} \mathrm{Na}, \mathrm{Nanofil}{ }^{\circledR}$ 757 and Somasif ${ }^{\circledR}$ ME100) leads to materials with no significant improvement in terms of Young's modulus and some decrease in strain and stress at break. This is typically what is expected for composites filled with low contents of non-compatibilised microfillers, confirming the XRD observations.

The effect of clay nature, for layered silicates organo-modified by the same ammonium cation, can be discussed when comparing the results obtained for Cloisite ${ }^{\circledR} 20$ A, Nanofil ${ }^{\circledR} 15$ and Somasif $\AA$ MAE. As expected for nanocomposites that exhibit intercalation and a significant extent of exfoliation, the Young's modulus is significantly increased and is even doubled in the case of Cloisite ${ }^{\circledR} 20 \mathrm{~A}$ or Nanofil ${ }^{\circledR} 15$. The increase in Young's modulus is less pronounced for Somasif ${ }^{\circ}$ MAE. This might indicate a lesser degree of exfoliation. No significant differences in properties at break can be detected for these samples, indicating a similar behaviour in terms of mechanism of rupture. In each case, the obtained values, compared to the EVA matrix alone, are slightly decreased. This may be due to the increase in Young's modulus which means that the materials are stiffer and therefore may be somehow a little more 'brittle'. From these observations, it can be concluded that the fracture behaviour is independent of the clay origin, fracture properties appearing to be related to the nature of the clay organo-modifier and state of nano-composite dispersion.

The effect of the clay organo-modifier (independent of the clay origin) can be discussed when comparing the results obtained for the organo-modified Cloisite ${ }^{\circ}-$ based nanocomposites. The highest Young's modulus is found for Cloisite ${ }^{\circledR} 20 \mathrm{~A}$, followed by Cloisite ${ }^{\circledR} 30 \mathrm{~B}$ and Cloisite ${ }^{\circledR} 25 \mathrm{~A}$. The high values found indicate a large extent of exfoliation even if intercalation is still observed. As far as properties at break are concerned, while Cloisite ${ }^{\circledR} 25 \mathrm{~A}$ is characterized by stress and strain values close to Cloisite ${ }^{\circledR} 20 \mathrm{~A}$ (already discussed here), Cloisite $\AA 30 \mathrm{~B}$ exhibits a significant increase in stress at break, while maintaining good strain at break properties. This might reflect the good interaction between the hydroxyl-functionalised ammonium cations that organomodify the clay and the acetate functions of EVA (reinforcement through H-bonding).

Table 3: Tensile properties of EVA and EVA-based (nano)composites (3 wt\% in inorganics)

\begin{tabular}{lccc}
\hline Filler & Stress at break (MPa) & Strain at break (\%) & Young's modulus (MPa) \\
\hline- & $28.4 \pm 0.7$ & $1406 \pm 28$ & $12.2 \pm 1.2$ \\
Cloisite ${ }^{\circledR} \mathrm{Na}$ & $25.9 \pm 1.0$ & $1403 \pm 27$ & $13.5 \pm 0.4$ \\
Cloisite ${ }^{\circledR}$ 20A & $25.8 \pm 1.3$ & $1231 \pm 46$ & $24.9 \pm 0.9$ \\
Cloisite ${ }^{\circledR}$ 25A & $26.2 \pm 1.2$ & $1259 \pm 25$ & $22.0 \pm 1.0$ \\
Cloisite ${ }^{\circledR}$ 30B & $30.7 \pm 0.9$ & $1266 \pm 24$ & $22.8 \pm 1.1$ \\
Nanofi1 ${ }^{\circledR ~ 757 ~}$ & $27.6 \pm 0.4$ & $1358 \pm 18$ & $11.6 \pm 0.8$ \\
Nanofi1 ${ }^{\circledR}$ 15 & $26.7 \pm 0.4$ & $1291 \pm 45$ & $24.0 \pm 0.5$ \\
Somasif ${ }^{\circledR}$ ME100 & $24.5 \pm 0.7$ & $1312 \pm 36$ & $12.4 \pm 0.3$ \\
Somasif ${ }^{\circledR}$ MAE & $25.1 \pm 2.2$ & $1270 \pm 51$ & $21.1 \pm 2.6$ \\
\hline
\end{tabular}



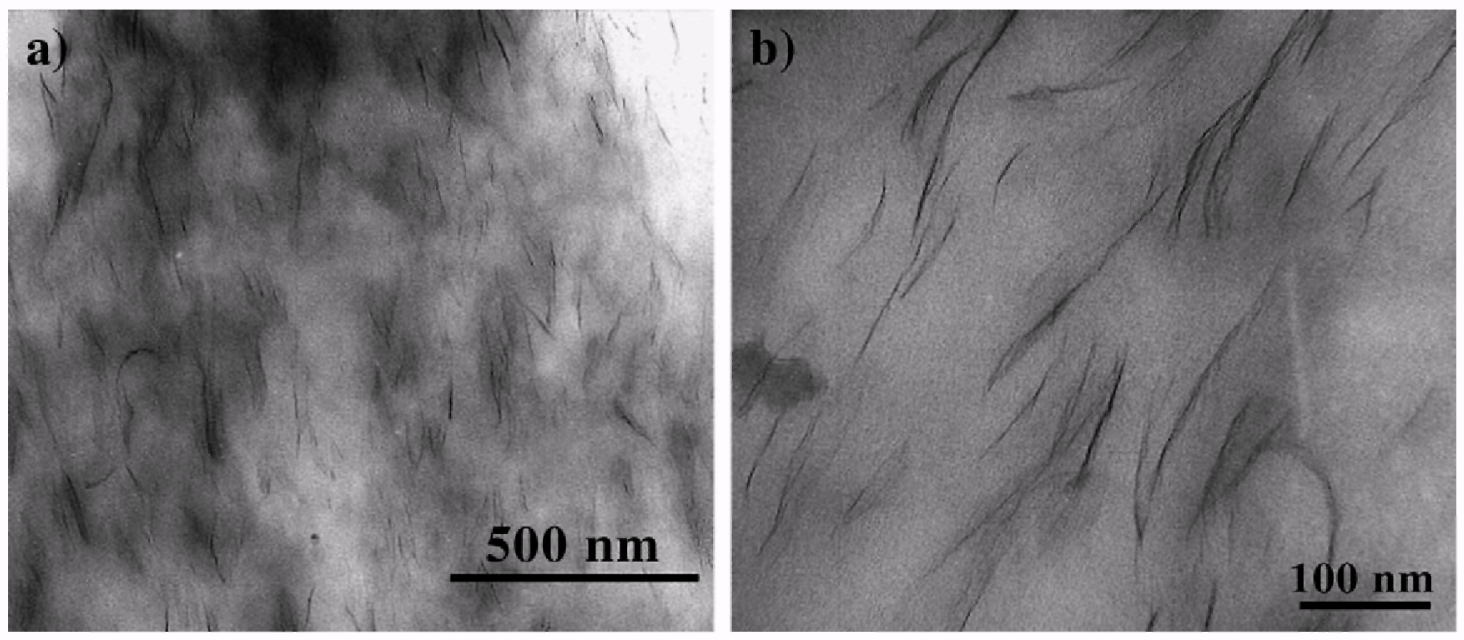

Fig. 3. TEM microphotographs of the nanocomposite based on EVA 5 wt\% Cloisite ${ }^{\circledR} 30 B$. (a) Low magnification, (b) high magnification.

\subsection{Thermogravimetric analysis}

The thermogravimetric analysis under air flow (thermo-oxidation) of the nanocomposites based on $3 \mathrm{wt} \%$ (in inorganics) of the various organo-modified clays have been carried out to study the effect of the clay origin and the type of organo-modifier on the resistance of the various nanocomposites towards thermal degradation.

The thermo-oxidation of ethylene vinyl acetate copolymer (EVA) takes place in two steps [9]. First, deacetylation is observed between 300 and $400{ }^{\circ} \mathrm{C}$, with production of gaseous acetic acid and formation of carbonecarbon double bonds along the polymer backbone. In a second step (between 400 and $500^{\circ} \mathrm{C}$ ), the unsaturated chains are oxidized and volatilised through statistical chain breaking.

Fig. 4 allows comparison of the effect of clay origin and nature (keeping the same organo-modifier) on resistance toward thermal degradation of the obtained nanocomposites. There is a clear dependence of the nature of the clay on both the first and the second degradation of the EVA matrix. In pure EVA, the maximum rate of weight loss for the first degradation event occurs at $437^{\circ} \mathrm{C}$ while its occurs at $355{ }^{\circ} \mathrm{C}, 358^{\circ} \mathrm{C}$ and $369{ }^{\circ} \mathrm{C}$ for Cloisite ${ }^{\circledR}$ $20 \mathrm{~A}$, Nanofil ${ }^{\circledR} 15$ and Somasif ${ }^{\circledR}$ MAE, respectively. The same trend is observed for the second degradation, with the maximum of weight loss rate located at $447^{\circ} \mathrm{C}$ for the pure EVA while it occurs at $479{ }^{\circ} \mathrm{C}, 489^{\circ} \mathrm{C}$ or $499^{\circ} \mathrm{C}$ for Cloisite ${ }^{\circledR} 20 \mathrm{~A}$, Nanofil ${ }^{\circledR} 15$ and Somasif $\AA$ MAE, respectively. When looking closely at the curves (and more especially at the derivative curves), one can observe that for every type of material, both the first and the second degradation start at the same temperatures. The thermal shift of the maximum of weight loss rate is mainly due to a slower increase of the rate with the temperature increase. Such information indicates that thermal degradation delay is mainly due to a decrease in the rate of evolution of the volatile products. The origin of such a shift in EVA matrices has been studied by Zanetti et al. [16]. The significant delay of weight loss in air has been attributed to the barrier effect promoted by the presence of dispersed clay platelets, whose exfoliated structure collapses upon matrix degradation, forming an insulating layer.

Indeed, such morphology modification induces a decrease in both the volatile thermo-oxidation products diffused out and oxygen diffusion from the gas phase into the polymer matrix. Fluoromica, such as Somasif® clay, is known to have wider platelets (200-500 $\mathrm{nm}$ in length) than commercially available montmorillonites such as Cloisite ${ }^{\circledR}$ or Nanofil ${ }^{\circledR}$ (usually between 100 and $300 \mathrm{~nm}$ ). When relatively well dispersed, the fluoromica-type nanoplatelets could act more efficiently as diffusion barriers than shorter montmorillonite-type platelets, inducing a much efficient delay in volatiles evolved from the thermally degraded EVA.

Such an effect, linked to the size of the platelets, is not detected for the samples based on clays having the same origin but differing by the nature of the organo-modifier, as observed for the Cloisite-based nanocomposites (Fig. 5). Indeed, while both XRD and TEM have shown that the nanocomposites based on Cloisite ${ }^{\circledR} 30 \mathrm{~B}$ are characterized by a much better dispersion of the clay nanoplatelets than for e.g., Cloisite ${ }^{\circledR} 25 \mathrm{~A}$, this 
improvement in dispersion does not seem to be sufficient to improve the delay in thermal volatilisation of the EVA matrix. As far as the first degradation of EVA (matrix deacetylation), Cloisite ${ }^{\circledR} 30 \mathrm{~B}$ seems even to have a small activating effect on the thermal volatilisation of acetic acid, while neither Cloisite ${ }^{\circledR} 20 \mathrm{~A}$ or $25 \mathrm{~A}$ significantly influence the rate of volatilisation.

This observation is even better observed on the second degradation step where no difference can be made between the three clays. As far as thermo-oxidative degradation is concerned, the main influencing factor appears to be the nature of the clay, probably due to variation in aspect ratios rather than the nature of the clay organo-modifier or the related state of dispersion of the clay nanoplatelets.

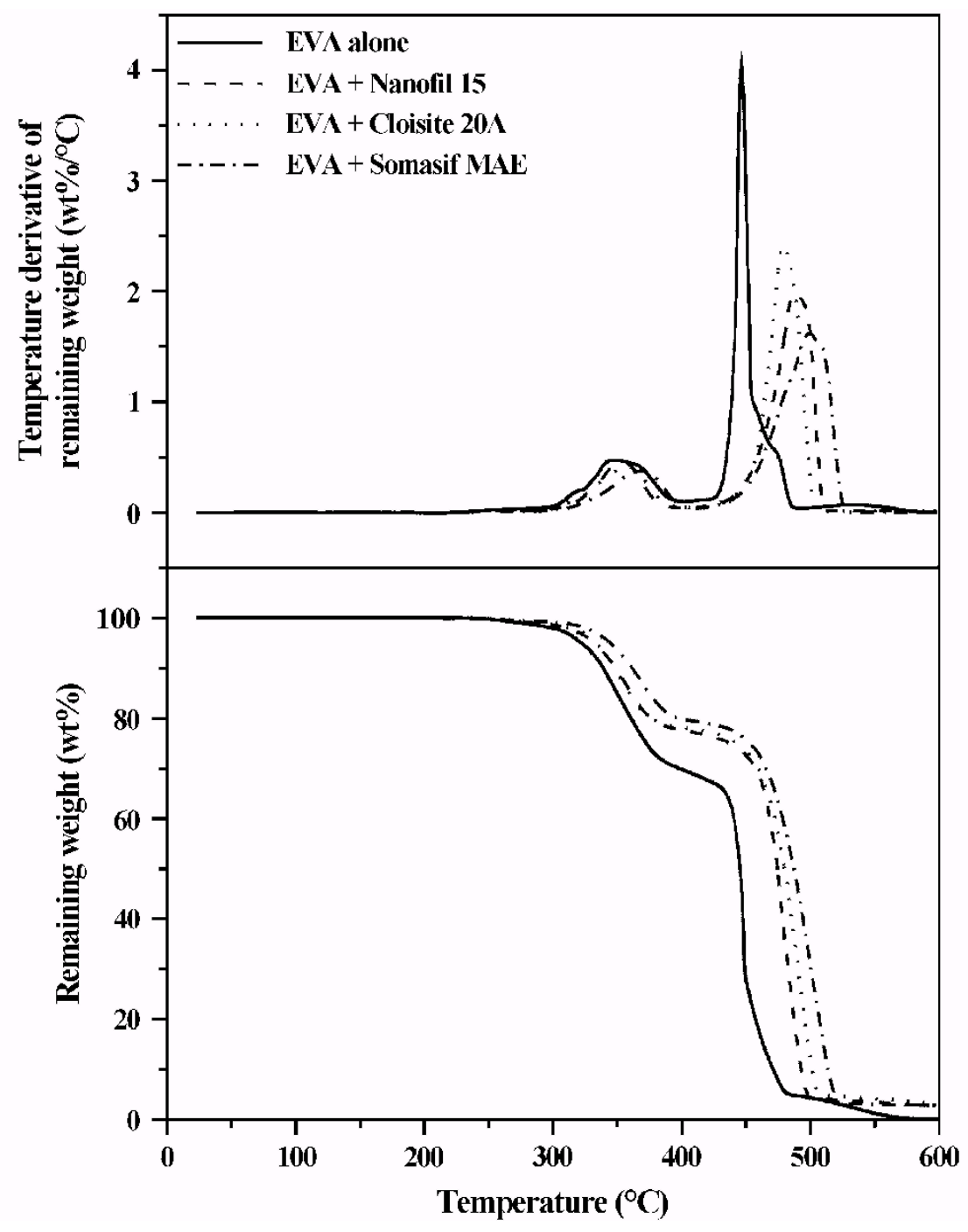

Fig. 4. Thermogravimetric analyses under air flow $(20 \mathrm{~K} / \mathrm{min})$ of EVA and EVA nanocomposites $(3 \mathrm{wt} \%$ in inorganics) based on various clays organo-modified by the same ammonium cation (dimethyl bis(hydrogenated tallowalkyl) ammonium). 


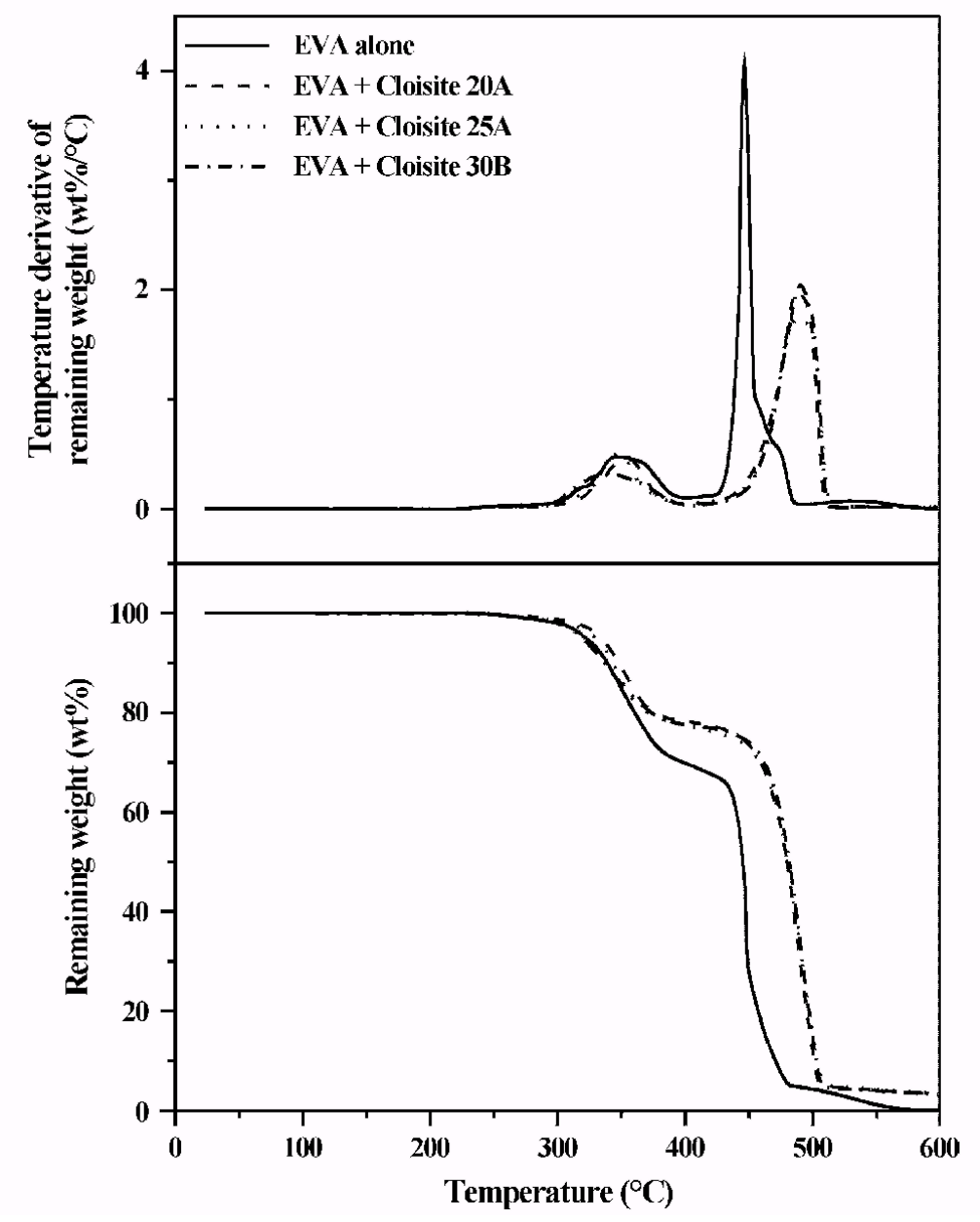

Fig. 5. Thermogravimetric analyses under air flow $(20 \mathrm{~K} / \mathrm{min})$ of EVA and EVA nanocomposites $(3 \mathrm{wt} \%$ in inorganics) based on Cloisite ${ }^{\circledR}$ clays organo-modified by various ammonium cations (see Table 1)

\section{Conclusions}

This study has rationalized the effect of clay nature and clay organo-modifier on the morphology, tensile and thermal degradation properties of nanocomposites obtained by melt blending in an EVA matrix containing 27 $\mathrm{wt} \%$ vinyl acetate. While all the tested organo-modified clays exhibit both intercalated and exfoliated structures, the nanocomposites based on Cloisite ${ }^{\circledR}$ 30B display the highest amount of exfoliation and clay stacking destruction, characterized by the absence of a characteristic XRD peak. This better filler dispersion might arise from interactions between the acetate functions of EVA and the hydroxyl-bearing ammonium cations that modifies Cloisite $\AA 30 B$. These interactions might also result in an increase in tensile stress at break for the Cloisite 30B-based nanocomposite, compared with the other clays. As far as the stiffness is concerned, a relation between the amount of exfoliation and the increase of the material's Young's modulus has been observed. In the case of mechanical (tensile) properties, variation of the organo-modifier nature (and its ability to promote exfoliation) has more influence than the nature of the clay itself. The reverse conclusion arises when thermal degradation properties are studied. In this case, the nature of the clay and more especially the aspect ratio of the nanoplatelets dominate the delay in thermal volatilisation of EVA during thermo-oxidation while the nature of the organo-modifier and the related state of dispersion of the clay nanoplatelets has no significant influence on this property.

\section{Acknowledgments}

Ph. D. and S. P. wish to thank 'Région Wallonne' for financial support in the frame of the Nanotechnology project: BINANOCO. LPCM and CERM thank the Belgian Federal Government Office of Science Policy (SSTC-PAI 5/3). M. A. and Ph. D. are much indebted to both 'Région Wallonne' and European Community 'FSE and FEDER' for financial support in the frame of Objectif-1 Hainaut: Materia Nova. 
Published in: Polymer degradation and stability (2005), vol. 90, iss. 2, pp. 288-294 Status: Postprint (Author's version)

\section{References}

[1] Alexandre M, Dubois Ph. Mater Sci Eng R 2000;28(1-2):1-63.

[2] Biswas M, Ray SS. Adv Polym Sci 2001;155:167-221.

[3] Schmidt D, Shah D, Giannelis EP. Curr Opin Solid State Mater Sci 2002;6:205-12.

[4] Zhang F, Sundararaj U. Polym Comp 2004;25(5):535-42.

[5] Suh IS, Ryu SH, Bae JH, Chang YW. J Appl Polym Sci 2004;94:1057-61.

[6] Jeon CH, Ryu SH, Chang YW. Polym Int 2003;52:153-7.

[7] Zhang W, Chen D, Zhao Q, Fang Y. Polymer 2003;44:7953-61.

[8] Li X, Ha C. J Appl Polym Sci 2003;87:1901-9.

[9] Riva A, Zanetti M, Braglia M, Camino G, Falqui L. Polym Degrad Stab 2002;77:299-304.

[10] Giannelli W, Camino G, Dintcheva NT, Lo Verso S, La Mantia FP. Macromol Mater Eng 2004;289:238-44.

[11] Alexandre M, Beyer G, Henrist C, Cloots R, Rulmont A, Jérôme R, et al. Macromol Rapid Commun 2001;22:643-6.

[12] Zanetti M, Camino G, Müilhaupt R. Polym Degrad Stab 2001;74:413-7.

[13] Hull TR, Price D, Liu Y, Wills CL, Brady J. Polym Degrad Stab 2003;82:365-71.

[14] Duquesne S, Jama C, Le Bras M, Delobel R, Recourt P, Gloaguen JM. Comp Sci Technol 2003;63:1141-8.

[15] La Mantia FP, Lo Verso S, Dintcheva NT. Macromol Mater Eng 2002;287:909-14.

[16] Zanetti M, Kashiwagi T, Falqui L, Camino G. Chem Mater 2002;14:881-7. 